LIPOVETSKY, G.; SERROY, J. La cultura-mundo. Respuesta a una sociedad desorientada. Barcelona: Anagrama, 2010.

Pedro Hellín ${ }^{1}$

Desde La era del vacío, a mediados de los ochenta, Lipovetsky llama a nuestra época hipermodernidad para designar la "sociedad postmoderna" y sus transformaciones individuales y colectivas. La cultura-mundo es una reflexión audaz que continua la línea central de su pensamiento, en el sentido de explorar lo que otros autores denominan postmodernidad. Junto a ese esfuerzo orientado a ampliar y profundizar la línea de su discurso central, Lipovetsky, con el apoyo de Serroy (director de cine y profesor), se propone avanzar un paso más allá en el análisis del papel de la cultura en el mundo del siglo XXI.

En esta segunda entrega de Lipovetsky y Serroy el escenario analítico ya no es únicamente la sala cinematográfica o la multitud de pantallas que propagan una hipermodernidad desregularizada en la que la narrativa clásica daba paso a lo multiforme, lo híbrido y lo plural. Ahora de lo que se trata es de analizar la cultura tomada como ejemplo y representación planetaria.

El término 'cultura-mundo' designa para ambos autores "la cultura extendida del capitalismo, el individualismo y la tecnociencia, una cultura globalizada que estructura de modo radicalmente nuevo la relación de la persona consigo misma y con el mundo". Para hacernos entender el significado de "cultura-mundo", Lipovetsky y Serroy recurren a desgranar y mezclar, recursos históricos, biográficos y económicos con los que apoyar e ilustrar su descripción de un mundo caracterizado por el triunfo del capitalismo, de la tecnociencia, del individualismo y del consumismo.

En un mundo marcado por estas cuatro características es evidente que la cultura ya no es lo que era en el siglo XX. Ya no es lo que Althusser, Castoriadis o buena parte del marxismo estructuralista francés consideraban "una superestructura de signos, perfume y ornato del mundo real". La cultura en el siglo XXI es en gran medida tecnocapitalismo global, industria cultural, consumismo, medios de comunicación y redes informáticas.

\footnotetext{
${ }^{1}$ Profesor Contratado Doctor. Imparte las asignaturas de Diseño de la Imagen Corporativa, y Sistemas y Procesos de la Publicidad y las Relaciones Públicas. Universidad de Murcia. Facultad de Comunicación y Documentación. Campus Universitario de Espinardo, s/n. 30100 Murcia. +34 868888 411. E-mail: phellin@um.es
} 
La cultura-mundo. Respuesta a una sociedad desorientada.

de Pedro Hellín

Atrás queda la época en la que la cultura era un sistema coherente que explicaba el mundo y que diferenciaba entre cultura popular y cultura ilustrada. La cultura, como afirman Lipovetsky y Serroy, inseparable ya de la industria comercial, tiene vocación planetaria y se infiltra en todas las actividades de la vida cotidiana.

La globalización de la cultura no significa suprimir las idiosincrasias nacionales, busca simplemente unificar el planeta a través del mercado. Curiosamente, quizá de forma contradictoria, el siglo XXI pide la rehabilitación del pasado, el culto a lo auténtico, la reactivación de la memoria religiosa e identitaria, las reivindicaciones particularistas.

Por otro lado, la dinámica hipermoderna no rivaliza con la cultura. Al contrario, la convierte en su principal rasgo, hasta el punto de que hoy se podría hablar de un “capitalismo cultural". De este modo, las industrias culturales y el universo digital se convierten en piezas esenciales del hipercapitalismo globalizado y de la cultura-mundo.

Las marcas y el propio capitalismo construyen a su vez una cultura conformada por un sistema de valores, metas y mitos caracterizados por la hipertrofia de la oferta comercial y la sobreabundancia de información e imágenes.

La cultura-mundo está, sin embargo, repleta de paradojas y de contradicciones. Lipovetsky y Serroy afirman que "también desorganiza a mayor escala las conciencias, las formas de vida, la existencia individual. El mundo hipermoderno está desorientado, inseguro, desestabilizado, no de manera ocasional, sino cotidianamente, de forma estructural y crónica. Y esto es nuevo.” Esta desorientación, nueva y excepcional, es precisamente una de las características centrales de la cultura-mundo.

Esta tremenda desorientación, individual y colectiva, no deja de ser sorprendente porque pocas veces la humanidad ha dispuesto de los recursos actuales. La eficacia de la medicina, la educación generalizada, el nuevo papel de la mujer, la liberalización de las costumbres y, en definitiva, una existencia enormemente facilitada por los adelantos de la ciencia y la técnica. Sin embargo, vivimos en un mundo ansioso y depresivo, generador de inquietudes de todo tipo y que ve un futuro cada vez menos prometedor.

Bajo la presión de las reivindicaciones particularistas y las dinámicas nacionalistas la cultura se ha convertido en el centro polémico de numerosos conflictos. Los debates sobre la laicidad, el islamismo, las reivindicaciones lingüísticas o el desgaste de la democracia contribuyen a situar la cultura en espacios contradictorios. 
Vuelve la cultura para dar a los individuos cierto dominio sobre su vida pese a sus conflictos psicológicos y a la desestructuración de la personalidad.

Hipercapitalismo, hipertecnología, hiperindividualismo e hiperconsumo son los principios estructurantes del mundo de la cultura-mundo en el siglo XXI. Un mundo en el que ha dejado de existir el antagonismo entre economía y cultura, a la vez que se producía la hipertrofia de esta última y su absorción por el orden comercial y el universo ciberespacio.

En el último tercio del libro, Lipovetsky y Serroy muestran cómo el mercado ha engullido el mundo del arte. La mutación sufrida por los museos de todo el planeta les sirve para apoyar su visión de la expresión artística como una actividad reestructurada por las lógicas del espectáculo y de las nuevas estrategias de seducción.

El museo, antes lugar de reflexión, de goce estético e incluso de recogimiento pasa a convertirse, por obra y gracia de los arquitectos de renombre, en espacio urbano y en “joyero-seducción”. El arte ya no se contempla con la veneración, el silencio y el recogimiento del pasado, sino con la despreocupación de las muchedumbres de vacaciones que siempre necesitan tener una cafetería o restaurante cool en el entramado del museo. Warhol derribó las fronteras entre el arte, la moda y la publicidad cuando se definió como "un artista comercial".

En el cierre de La cultura-mundo,Lipovetsky y Serroy tratan de suavizar su visión pesimista y ambivalente del mundo de la cultura en el siglo XXI. Y nos recuerdan que, pese a todo, la cultura del entretenimiento y su estética fácil no impide la reflexividad o la innovación de los individuos que buscan comprender o mejorar el mundo. El individuo hipermoderno no tiene por qué contentarse con los meros placeres consumistas, también busca ser agente, expresarse, dar su opinión y participar en la vida pública.

Al final, Lipovetsky y Serroy buscan dar paso a la esperanza de una cultura que, más allá del entretenimiento y del mercado, impulse la formación artística a través de la educación de los jóvenes. Más allá del consumo la cultura es, todavía hoy, esperanza (esto mismo fue dicho por Lipovetsky en su conferencia de la ECA).Sólo la educación está en disposición de poder convertir la cultura no en un objeto de evasión dictaminado por el mercado, sino en un instrumento para explicarnos a nosotros mismos y entender el mundo en el que desplegamos nuestra existencia. 
La cultura-mundo. Respuesta a una sociedad desorientada.

de Pedro Hellín

\section{ALGUNAS IDEAS}

La cultura-mundo significa el fin de la heterogeneidad tradicional de la esfera cultural y una cada vez mayor universalización de la cultura comercial. Una cultura que conquista las esferas de la vida social, los estilos de vida y casi todas las actividades humanas. La cultura es inseparable de la industria comercial. El mercado coloniza la cultura y los modos de vida y los somete a sus valores de eficacia. La cultura se piensa en términos de mercado, de cifras de negocios, de maximización de intereses. Esta lógica ha derribado las clásicas jerarquías entre cultura noble y cultura popular. Se han diluido las oposiciones entre cultura y entretenimiento, entre reflexión y distracción, cultura y espectáculo. La cultura del siglo XXI está creada por todo el mundo, no por una élite ilustrada. Todo está en la misma línea de salida y los lugares de privilegio e influencia los establece el mercado. La cultura está en manos de la rentabilidad económica.

También la cultura-mundo testimonia la explosión del universo de la comunicación, la información, la mediatización. Se produce un desarraigo de la cultura global, se altera nuestra relación con el tiempo y las distancias («se estornuda un cualquier parte del mundo y todo el planeta tose»), pero simultáneamente se crean filias y apegos destinados a satisfacer los particularismos locales, el orgullo territorial, el respeto a la memoria y a las raíces. A pesar de que absorbemos una producción cultural planetaria convertida en artículo de consumo, los autores defienden que "no vamos hacia un mundo con gustos, modos de vida y costumbres idénticos, sino hacia culturas diferentes reestructuradas por las mismas lógicas del capitalismo y de la técnica, del individualismo y el consumismo".

Según Lipovetsky (2006), la sociedad del Hiperconsumo se caracteriza por:

- Pérdida de los "referentes de clase" tradicionales

- Nuevo consumidor voluble, fragmentado, desregulado

- Consumo más experiencial, emocional que estatutario

- Se consume más para uno mismo que para obtener el reconocimiento del otro

- Los consumidores están "poseidos" por el miedoano experimentar sensaciones nuevas 
La cultura-mundo. Respuesta a una sociedad desorientada.

- Comprar es jugar (subjetividad)

El hiperconsumo es emocional y como tal inunda las parcelas no económicas de nuestra vida (familia, religión, sindicalismo, procreación, escuela, ética)

Cuanto más se impone la comercialización de la vida, más celebramos los Derechos Humanos. El consumo es contemporáneo del desarrollo de los sentimientos.

\section{LA CULTURA-MUNDO}

- Lo visto para la nueva sociedad de consumo es extensible a la cultura.

- La cultura de nuestra época no es el conjunto de normas sociales heredadas del pasado y la tradición (cultura antropológica), ni el mundo de las artes y las letras (alta cultura).

- La cultura actual es un sector económico en plena expansión: “capitalismo cultural"

- La cultura-mundo describe el sistema económico-cultural del hipercapitalismo globalizado

- Origen de la Cultura-Mundo:

- Fin del enfrentamiento entre cultura y economía

- Poco dinamismo de la esfera (el mundillo) cultural

- Absorción de la cultura en el orden comercial

- Industrias culturales, ciberespacio (fundamentales en la cultura-mundo)

- Los bienes comerciales (objetos, moda, marca) acaban formando parte de esta cultura de nuevo género, de consumo generalizado.

- Reciclado, el arte, también se convierte en elemento constitutivo de esta cultura, obedeciendo las leyes de la economía (“Soy un artista comercial”, Warhol)

En la época de la cultura-mundo, la cultura se vuelve mundo de marcas y consumo, y el mundo comercial se vuelve más o menos comercial.

- Características de la Cultura-Mundo: 
La cultura-mundo. Respuesta a una sociedad desorientada.

- Es la primera cultura no producida por una élite social e intelectual, sino por todo el mundo.

- Las industrias culturales modernas, a través del cine, la música y los audiovisuales, se dirigen a la inmensa mayoría, inaugurando una nueva etapa en la difusión de la cultura.

- Los productos culturales se simplifican al máximo, para exigir el menor esfuerzo posible a su público.

- Al estar destinada al consumo comercial, la cultura de masas debe renovar su oferta sin cesar, con productos que necesitan ser novedosos, pero sin abandonar los estándares industriales.

Artigo recebido: 03/2012

Artigo aprovado: 06/2012 